\title{
Does Ethnicity Matter? Social Workers' Personal Attitudes and Professional Behaviors in Responding to Child Maltreatment
}

\author{
Vicki Ashton
}

\begin{abstract}
This study examined differences in the attitudes of professional social workers regarding corporal punishment and the perception and reporting of child maltreatment, according to the worker's ethnic group membership (Asian, Black American, Black Caribbean, Hispanic, and non-Hispanic White). Data were obtained by mailed questionnaires from 808 members of the New York City chapter of NASW. Data were analyzed by analysis of variance. Results indicate that approval of corporal punishment and perception of maltreatment differed according to ethnic group membership. However, ethnicity had no effect on the likelihood of reporting maltreatment. Findings suggest that social work values override personal-culture values in the execution of jobrelated responsibilities. Implications for education and practice are discussed.
\end{abstract}

Keywords: Professional socialization and ethnicity; culture, attitudes and social work practice; personal values and professional practice; corporal punishment and maltreatment

\section{INTRODUCTION}

Child maltreatment remains a serious social problem affecting more than one million children and families each year (Sedlak et al., 2010). Health and social service professionals are required by law to report suspected abuse and neglect, yet many incidents of suspected abuse are not reported; moreover, there is often disagreement as to what constitutes maltreatment (Sedlak et al., 2010). Research on mandated reporters suggests that the process of identifying and responding to child maltreatment is a complex phenomenon that involves at least three phases: observing a given situation; assessing and labeling parental behavior; and responding to that behavior. Each phase of the process is filtered through the personal characteristics of the observer. These personal characteristics include attitudes and opinions which direct behavior. For example, a worker's opinion of the severity of parental behavior in an incident of probable maltreatment is related directly to the likelihood that an incident is reported (Ashton, 1999; Ashton, 2001; Morris, Johnson, \& Clasen, 1985; Zellman, 1992). It has also been documented that opinions of mandated reporters differ in what they consider to be maltreatment and that these differences in perception can be attributed to worker attitudes about parenting and discipline (Ashton, 2001; Morris et al., 1985).

An individual's attitudes about parenting and discipline are shaped by experiences that are to a considerable extent marked by socio demographic traits, of which ethnicity is salient (Green, 1978; Korbin, 1994; Webb, 2001). Ethnicity remains an "enduring dimension" of American life (Devore \& Schlesinger, 1999, p.4) and an important social construct (Dolliver, 2008; Miehls, 2001). Ethnicity represents a "peoplehood" based on common physical appearance, language, and homeland, and on norms, traditions, values,

Vicki Ashton, D.S.W., is a professor of Social Work at York College of The City University of New York, Department of Social Sciences. This research was supported by National Institutes of Health grant \#41385. The author is grateful to W.

Cody Wilson and Beth S. Rosenthal for reading earlier drafts of this work and for their invaluable insight and suggestions.

Copyright (C) 2010 Advances in Social Work Vol. 11 No. 2 (Fall 2010), 129-143 
and history that make up the content of culture (Devore \& Schlesinger, 1999; Korbin, 1994). Ethnic group membership includes a common approach for solving problems of daily living which is based on a historical development for coping that has worked for a given group (Devore \& Schlesinger, 1999). These problem solving approaches and the rationale surrounding them become subtle influences that shape attitudes, opinions, and behavior such as parenting (Devore \& Schlesinger, 1999; Webb, 2001).

A number of studies have found differences in the use and endorsement of corporal punishment according to ethnic group membership, with Black Americans being the most frequent users of corporal discipline, Whites the least and Hispanics in between (DeaterDeckard, Lansford, Dodge, Pettit, \& Bates, 2003; Mosby, Rawls, Meehan, Mays, \& Pettinari, 1999). Asian (Lau, Takeuchi, Alegri'a, 2006) and Caribbean (Smith \& Mosby, 2003) parents have also been found to be more authoritarian and more favorable toward corporal punishment than White non-Hispanic parents. In addition to ethnicity being related to the endorsement of corporal punishment as an effective means of discipline, ethnicity also appears to influence the perception of child maltreatment (Ashton, 2004; Hong \& Hong, 1991; Korbin, 1994).

Among social workers, personal attitudes and opinions that influence professional behavior are tempered and shaped by the norms, values, and ethics acquired through the process of professional socialization (Hantman et al., 2006). Professional socialization can be defined as the acquisition of specific knowledge, skills, and values through the process of social work education (Barretti, 2003). The purpose of social work education is to prepare competent and effective professionals who apply critical thinking skills within the context of professional social work practice and who understand the value base of the profession and practice accordingly (Council on Social Work Education [CSWE], 2008). Throughout the educational process, students acquire knowledge of social work principles and ideals at the same time they are called on to evaluate their own personal values (Abrams \& Mojo, 2009; CSWE, 2008; Devore \& Schlesinger, 1999). Throughout social work education and into professional practice, social workers are required to scrutinize their intervention decisions and to be aware of the ways in which their value preferences influence and shape their practice (Mattison, 2000). The educational process of self-assessment recognizes that much of social work practice involves discretionary judgments which require social workers to effectively resolve conflicts between their personal and professional values. A desired outcome of social work education is the internalization of social work norms and values that allows workers to effectively regulate their practice and appropriately use their autonomy (Costello, 2004). Professional socialization involves the integration of professional and personal identities (Hantman et al., 2006) so that "one's identity as social worker is inseparable from the practice of social work" (Jeffery, 2005, p. 419). The process of achieving integration requires some struggle with personal and professional value conflicts, an ability to set personal preferences aside, and the willingness to adopt professional values in accomplishing work with clients (Johnson \& Yanca, 2007; Tam \& Coleman, 2009).

It is generally presumed that there is an eventual fit between personal and professional values and that practitioners reach a similar level of assimilating social work ideals, attitudes, knowledge and skills (Spano \& Koenig, 2007). Yet research on social 
work education finds that the process of professional socialization is not uniform; it does not produce a homogenous group of practitioners with the same attitudes and values (Barretti, 2003; Costello, 2004). In fact, there are some studies that suggest that persons of color have a different socialization experience into social work than whites (Barretti, 2003, Daniel, 2007; Jeffery, 2005).

The literature on professionalization raises many questions including the question, what happens when there are conflicts between personal and professional values? Do social workers disregard one system over the other or is a compromise made? Several studies have found that personal attitudes toward corporal punishment impact directly on a worker's judgment of the severity of an incident of probable child maltreatment and relate both directly and indirectly to the likelihood of reporting an incident to child protective services (Ashton, 2001; Morris et al., 1985). Previous studies have examined the relationship between attitudes toward corporal punishment and the reporting of child maltreatment among non professionals (Ashton, 2001; Bluestone, 2005; Ibanez, Borrego, Pemberton, \& Terao, 2006) and physicians (Morris, Johnson, \& Clasen, 1985); however, no study has examined one of the largest groups of mandated reporters-social workers. Nor has any study examined the effect of ethnicity on professional decision making among mandated reporters. Ethnicity is an important personal characteristic affecting perception and response to child maltreatment. Professional socialization provides a lens that presumably supersedes the personal perspective.

Race and ethnicity are often used interchangeably; however, in this study, the term "ethnicity" is used to reflect the interest on culture rather than biology (Webb, 2001). This study examines differences in the personal values and attitudes of professional social workers regarding corporal punishment according to ethnic group membership. The study also examines how ethnicity is related to the workers' professional behavior in the identification and reporting of probable child maltreatment. Based on the literature, three hypotheses guided the study:

1. There is a difference in approval of corporal punishment according to ethnic group membership. It is expected that White social workers will be less approving of corporal punishment than other ethnic groups.

2. There is a difference in the perception of the seriousness of an incident of probable maltreatment according to ethnic group membership. It is expected that White social workers will perceive incidents of probable maltreatment as more serious than other ethnic groups.

3. There is a difference in the reporting of child maltreatment according to ethnic group membership. It is expected that White social workers will be more likely to report incidents of probable child maltreatment than other ethnic groups.

\section{METHOD}

This was a cross sectional, correlational study. Data were collected using a mailed printed questionnaire. The population of interest in this study was professional social 
workers working with families and children in an agency setting in the New York City metropolitan area.

The study sample comprised 808 social workers who were systematically randomly selected from a list of the members of the New York City chapter of the National Association of Social Workers (NASW). Four thousand one hundred ninety four members $(4,194)$ were randomly selected from the full membership and were mailed the study questionnaire. Three follow-up communications were sent at three-week intervals, encouraging the recipients to participate in the study by completing the questionnaire. The third reminder included a short postcard questionnaire requesting selected demographic information if the person was unwilling or unable to fill out the longer questionnaire.

One thousand eight hundred fifty five $(1,855)$ individuals returned the questionnaire and 257 individuals returned the postcard questionnaire for a total response rate of $50 \%$. Those who returned the postcard were similar to those who completed the full questionnaire except that they were slightly older and were less likely to work with families or children and therefore were not members of the population of interest in this study. Of those who returned the questionnaire, 808 indicated that they were employed in agencies serving families and/or children and completed the questions pertinent to this study. Those 808 respondents comprise the sample of professional social workers for this study.

\section{Sample Characteristics}

The sample of 808 participants was predominately Caucasian (67\%) and female (78\%). Approximately 10\% were Black American; 4\% were Black Caribbean; 3\% were Asian; $12 \%$ were Hispanic; and 3.7\% "other". This last category consisted of persons who identified themselves as "American Indian/Alaskan Native" $(\mathrm{n}=3)$ or "other" and described themselves as multi ethnic, multi racial $(n=27)$. The mean age for the sample was 45 . Most (90\%) had a Master's degree as the highest level of their education. The sample had a mean of 13 years of professional experience; Whites had the most years, Hispanics the least (Table 1). Most of the sample had received some training in the area of child abuse; proportionately, persons categorized "other" and Black Caribbeans received the most training, Whites the least (Table 1).

\section{Measurement}

The independent variable "ethnicity" was measured by asking respondents to select the one ethnic group they identified with most from seven categories: American Indian/Alaskan Native, Asian/Asian American/Pacific Islander, Black/African American, Black/African Caribbean, Latin/Hispanic, White (non-Hispanic) and other. Respondents who identified themselves as American Indian/Native Alaskan or "other" were combined into one category, "other." Responses "were dichotomized into " 1 " for the selected ethnic group and "0" for all others. 
Table 1. Sample Characteristics: Frequencies and Percentages $(\mathbf{n}=\mathbf{8 0 8}$ unless specified)

\begin{tabular}{|c|c|c|}
\hline Age: & Mean 45 years & SD 12.3 \\
\hline Gender: $(n=806)$ & $\underline{\mathrm{N}}$ & $\underline{\text { Percent }}$ \\
\hline Male & 179 & 22.2 \\
\hline Female & 627 & 77.8 \\
\hline \multicolumn{3}{|l|}{ Educational level: } \\
\hline $\mathrm{BA} / \mathrm{BS}$ & 28 & 3.5 \\
\hline Masters & 734 & 90.7 \\
\hline $\mathrm{Ph} . \mathrm{D} / \mathrm{DSW}$ & 46 & 5.7 \\
\hline \multicolumn{3}{|l|}{ Race/ethnicity: } \\
\hline Asian & 26 & 3.2 \\
\hline Black American & 82 & 10.1 \\
\hline Black Caribbean & 33 & 4.1 \\
\hline Hispanic & 94 & 11.6 \\
\hline White & 543 & 67.2 \\
\hline Other & 30 & 3.7 \\
\hline Years of experience by ethnic group $(n=799)$ & Mean & SD \\
\hline Asian & 10.5 & 9.9 \\
\hline Black American & 12.9 & 10.6 \\
\hline Black Caribbean & 11.5 & 8.9 \\
\hline Hispanic & 8.9 & 7.2 \\
\hline White & 14.6 & 11.3 \\
\hline Other & 10.2 & 9.1 \\
\hline Total Sample & 13.5 & 10.8 \\
\hline 10 hours or more training by ethnic group & & $\underline{\text { Percent }}$ \\
\hline Asian & & 27 \\
\hline Black American & & 29 \\
\hline Black Caribbean & & 42 \\
\hline Hispanic & & 31 \\
\hline White & & 19 \\
\hline Other & & 43 \\
\hline
\end{tabular}

There were three dependent variables: approval of corporal punishment, perception of maltreatment, and likelihood of reporting maltreatment. Each dependent variable was measured using multi-item additive scales. 
"Approval of corporal punishment" was measured by a five-item scale adapted from Danso, Hunsberger, \& Pratt (1997). Each item has 8 response alternatives ranging from 1 "very strongly disagree" to 8, "very strongly agree." An example item asks the respondent to rate her or his level of agreement with the statement, "A good firm spanking can be one of the best ways to teach children right from wrong." The scores for all five items were added together. The scale has face content validity and good internal consistency with a reliability coefficient of .88 with the Danso, Hunsberger, Pratt sample (1997) and of .79 with this study sample.

"Perception of maltreatment" was measured by a multi-item additive scale using eight vignettes adapted from Hong and Hong (1991) and from cases known to the local child protective agency. Each vignette describes parental behavior that ranged from what could be considered moderate maltreatment to behavior considered severe maltreatment (Figure 1). Respondents were asked to rate the behavior of the parent on a Likert scale of "seriousness" from 1 to 7, with " 1 " being "not serious" and "7" being "very serious". Responses to the eight items were added together for a single score for "perception" (alpha .76).

"Likelihood of reporting" was measured by using the same eight vignettes of probable maltreatment. (These vignettes had been pre tested and rated for seriousness in a previous study by a sample of entry-level social service workers [Ashton, 2004]. On a scale of 1, "not serious" to 7, "very serious", the vignettes in this study ranged in seriousness from 5.3 to 6.8 ; thus, all of the vignettes represented reportable situations).

In the current study, respondents were asked to read each vignette and indicate the likelihood that they would report the incident to child protective services. Ratings ranged from 1 (almost certain not to report) to 5 (almost certain to report). The responses for all eight vignettes were summed to give an overall score for the respondent's "likelihood of reporting" (alpha .77).

\section{Figure 1. Case Vignettes}

1. Both parents work long hours; they leave very early in the morning and come home late at night. Their nine-year-old son is left on his own. The boy gets himself ready for school in the morning and lets himself in after school. The parents tell their son to eat food prepared and left in the refrigerator, warming it up if he wants. He usually eats it cold. He goes to bed by himself because his parents are usually not back by his bedtime.

2. A sixteen-year-old yells and curses at his parents during a recent argument. His parent punches him in the mouth.

3. The classroom teacher notices that a nine-year-old boy has red marks on his palms and legs. When asked about the marks, the boy tells the teacher that yesterday he went to a friend's house to play instead of going home to do his homework. When his father found out, he hit him on the palms and legs repeatedly with a stick. The child says that his father does this whenever he does not do his homework. 
4. A six-year-old wets the bed. Parents punish the child by immersing his lower body in a tub of very hot water.

5. Recently when asked a question, a 10-year old child mumbled a rude answer under his breath. His parent banged the child against the wall, bruising his shoulders.

6. A 12-year-old is caught stealing candy from the corner store. When his parents found out what the child did, they beat him with a stick and burned a mark on his arm to remind him not to steal again.

7. The parents discipline their eight-year-old child by hitting him with a strap whenever he misbehaves.

8. A family recently arrived in the metropolitan area from a rural location. Last week after school, their 10-year-old son went off with a group of new friends instead of coming straight home. His parents disciplined him in their usual way, which is to make him kneel in the closet for several hours.

\section{Analysis}

The frequency distributions of demographic variables, "approval of corporal punishment", "perception of maltreatment" and "likelihood of reporting" were described. Zero order correlations were obtained for key demographic variables, independent, and dependent variables. The hypotheses were tested using analysis of variance (ANOVA). The large sample size of 808 with six groups used in the ANOVA has the statistical power to detect even a small relationship $(\eta=.10)$ at the .01 level of significance $99 \%$ of the time (Cohen, 1988).

\section{RESULTS}

The sample as a whole varied considerably in their level of approval of corporal punishment, perception of maltreatment, and likelihood of reporting. The theoretical range of scores for approval of corporal punishment was 5 to 40; the actual range of scores was 5 to 38 . The mean score was 14.3 with a standard deviation of 7.8. Most of the respondents did not endorse corporal punishment highly but a minority did.

As a whole, the sample tended to perceive the situations of probable maltreatment as relatively serious; however, some respondents did not see the situations as serious. The theoretical range of scores was 8 to 56; the actual scores ranged from 25 to 56 . The mean score for the sample was 49 with a standard deviation of 4.8. The distribution was negatively skewed; more than half the sample had scores of 50 or above.

The actual range for likelihood of reporting was the same as the theoretical range, 8 to 40 . Some of the respondents would not have reported any of the cases of possible child maltreatment to child protective services, while others would have reported every case including those with moderate levels of seriousness. Nonetheless, the mean score for reporting was 34.1 (standard deviation 4.4) indicating that most of this sample would report most of the cases (Table 2). 
Table 2. Descriptive Statistics for Approval of Corporal Punishment, Perception of Maltreatment and Likelihood of Reporting $(\mathbf{N}=\mathbf{8 0 8})$

\begin{tabular}{lccc}
\hline Total Sample & $\begin{array}{c}\text { Approval of } \\
\text { corporal } \\
\text { punishment }\end{array}$ & $\begin{array}{c}\text { Perception of } \\
\text { maltreatment }\end{array}$ & $\begin{array}{c}\text { Likelihood of } \\
\text { reporting }\end{array}$ \\
\hline Mean & 14.27 & 49.51 & 34.12 \\
Median & 13.00 & 50.00 & 35.00 \\
Mode & 5.00 & 50.00 & 34.00 \\
Std. Deviation & 7.84 & 4.84 & 4.42 \\
Skewness & .642 & -1.012 & -1.069 \\
\hline
\end{tabular}

Correlation analysis shows several demographic variables-age, education, experience and training - related to the independent variable, ethnicity. Age, education and training are also related to one of the dependent variables, approval of corporal punishment (Table 3). There were no correlations between demographic variables and any other dependent variable.

The first hypothesis is confirmed by the statistical analysis. ANOVA showed significant difference between means for approval of corporal punishment according to ethnicity $(\mathrm{F}=24.9 ; \mathrm{p} .<.0001)$. The sample mean for approval of corporal punishment was 14.3. Black Americans had the highest approval rate with a mean of 20.4, followed by Black Caribbeans (mean, 18.1), Hispanics, Asians, and "other", each with a mean of approximately 17 . Whites had the lowest approval score with a group mean of 12.4. Ethnic group membership had a medium effect on approval of corporal punishment $(\eta=$ .36) (Rosenthal, 2001).

The second hypothesis is also confirmed. ANOVA showed a difference in perception of maltreatment $(\mathrm{F}=2.4 ; \mathrm{p}<.05)$ according to ethnicity. An ANOVA post hoc Tukey test for multiple comparisons identified a difference between Black Americans and Whites and Black Americans and Hispanics. There were no other between-group differences. Ethnic group membership had a small effect on perception of maltreatment $(\eta=.12)$, (Table 4).

The third hypothesis was not supported by the data. ANOVA showed no difference between ethnic groups in their likelihood of reporting maltreatment. There was virtually no association between ethnicity and reporting $(\eta=.08)$. 
ADVANCES IN SOCIAL WORK, Fall 2010, 11(2)

Table 3. Zero Order Correlations between Demographic, Independent and Dependent Variables $(\mathbf{n}=\mathbf{8 0 8})$

\begin{tabular}{|c|c|c|c|c|c|c|c|c|c|c|c|c|c|}
\hline & Gender & Education & Experience & Training & Asian & BlkAm & BlkCar & Latin & White & Other & Approval & Perception & Report \\
\hline Age & $-.12 *$ & $.30^{*}$ & $.72 *$ & $-.22 *$ & -.05 & -.03 & $-.12 *$ & $-.14 *$ & $.21^{*}$ & -.05 & $-.14 *$ & .03 & -.00 \\
\hline Gender & & -.09 & -.08 & .02 & -.00 & .07 & .00 & -.01 & -.02 & -.04 & -.06 & .05 & .03 \\
\hline Education & & & $.33^{*}$ & $-.18 *$ & .03 & $-.11 *$ & -.07 & -.09 & .18 & -.06 & $-.11^{*}$ & -.01 & -.04 \\
\hline Experience & & & & $-.23 *$ & -.05 & -.01 & -.03 & $-.15^{*}$ & $.16^{*}$ & -.06 & -.09 & -.01 & .02 \\
\hline Training & & & & & .00 & .09 & $.11^{*}$ & .08 & $-.20^{*}$ & .10 & $.13^{*}$ & -.08 & .02 \\
\hline \multicolumn{14}{|l|}{ Ethnicity } \\
\hline Asian & & & & & & & & & & & .05 & -.02 & -.06 \\
\hline Blk American & & & & & & & & & & & $.26^{*}$ & $-.11 *$ & -.04 \\
\hline Blk Caribbean & & & & & & & & & & & .10 & .02 & .04 \\
\hline Latin & & & & & & & & & & & $.13^{*}$ & .04 & .02 \\
\hline White & & & & & & & & & & & $-.35^{*}$ & .04 & .02 \\
\hline Other & & & & & & & & & & & .07 & -.01 & -.01 \\
\hline
\end{tabular}

$* \mathrm{p}<.05$ (Bonferroni correction for multiple computations, $\mathrm{C}=14$ ). 
Table 4. Analysis of Variance for Approval of Corporal Punishment, Perception of Maltreatment and Likelihood of Reporting Maltreatment by Ethnic Group $(n=808 ; d f=5,807)$

\begin{tabular}{|c|c|c|}
\hline \multicolumn{3}{|c|}{ Approval of corporal punishment } \\
\hline & Mean & SD \\
\hline Asian & 16.6 & 7.5 \\
\hline Black American & 20.4 & 8.2 \\
\hline Black Caribbean & 18.1 & 8.1 \\
\hline Hispanic & 17.1 & 8.1 \\
\hline White & 12.4 & 6.8 \\
\hline \multirow[t]{2}{*}{ Other } & 17.0 & 9.2 \\
\hline & $F=24.9$ & $\mathrm{p}<.0001$ \\
\hline \multicolumn{3}{|c|}{ Perception of maltreatment } \\
\hline & Mean & SD \\
\hline Asian & 49.1 & 4.5 \\
\hline Black American & 47.9 & 5.4 \\
\hline Black Caribbean & 50.0 & 5.2 \\
\hline Hispanic & 50.1 & 4.5 \\
\hline White & 49.6 & 4.7 \\
\hline \multirow[t]{2}{*}{ Other } & 49.4 & 4.9 \\
\hline & $F=2.4$ & $\mathbf{p}<.05$ \\
\hline \multicolumn{3}{|c|}{ Likelihood of reporting } \\
\hline & Mean & SD \\
\hline Asian & 32.6 & 4.8 \\
\hline Black American & 33.6 & 4.2 \\
\hline Black Caribbean & 35.1 & 3.5 \\
\hline Hispanic & 34.4 & 4.4 \\
\hline White & 34.2 & 4.4 \\
\hline \multirow[t]{2}{*}{ Other } & 33.9 & 6.2 \\
\hline & $F=1.2$ & NS \\
\hline
\end{tabular}

\section{DISCUSSION}

The reader should exercise some caution in interpreting the results of this study. First, the percentage of minority respondents is rather low. However, this sample comprised higher proportions of non Whites than the most recently reported national sample of social workers (Gibelman \& Schervish, 1997). Second, the data were obtained from a sample of New York City social workers who were members of their local chapter of NASW; therefore, application of the findings to social workers outside of the sample population should be tentative. Finally, the vignettes used in this study are predominately 
incidents of physical abuse; there is only one incident of neglect and none of emotional or sexual abuse.

The study has strength in that it employed a representative sample large enough to detect fairly small relationships among the variables (Cohen, 1988) and the reliabilities of the three multi-item measures $(.76, .77$ and .79$)$, though not excellent, are reasonably good and well within the range of reliabilities found in social science research. In addition, while vignettes in general have limitations in that they cannot portray all the information necessary to make an actual assessment and while the vignettes in this study are imperfect, vignettes have been used successfully in research to indicate probable decision-making (Ashton, 2004; Zellman, 1992).

The findings of this study suggest that professional socialization has an impact at the most critical point-professional practice. This sample of social workers varied significantly in their personal approval of corporal punishment according to ethnic group membership. Asian, Black American, Black Caribbean, Hispanic, and other non-White social workers, all endorsed corporal punishment as an appropriate form of discipline more so than did Whites. The attitudes of these social workers of color mirrored the attitudes of their related ethnic groups within the general population (Deater-Deckard et al., 2003). Ethnocentric attitudes appeared to be most prevalent among Black American social workers, who differed also in their perception of maltreatment, i.e. Black American social workers had the lowest mean score (47.9) for the perception of the seriousness of the eight incidents of maltreatment (Table 4). Nonetheless, ethnic group differences in perception of maltreatment were considerably smaller than ethnic group differences in approval of corporal punishment, suggesting the effectiveness of professional socialization and training.

Professional socialization appears to have occurred among all ethnic groups in the area where it is arguably most important, in practice. The desired outcome of child safety took precedence; these workers seemed to be able to put aside their personal opinions and protect children in need. When it came to responding to maltreatment, ethnic group membership did not matter and most of the sample regardless of ethnicity indicated that they were likely to report most of the cases of probable maltreatment. Professional socialization overrode personal opinions when it came to required action.

The findings from this study have implications for social work education. Social work education is committed to exploring diversity (CSWE, 2008) and has done so for at least two decades by including cultural competency and ethnic sensitivity in the curriculum (Abrams \& Gibson, 2007). The latest issue of CSWE accreditation standards calls for school social work programs to "engage diversity and difference in practice" (CSWE, 2008). However, a frequent criticism of the diversity/cultural competence curricula is that there are few tangible learning or practice outcomes (Abrams \& Mojo, 2009). The results of this study indicate that social work education should continue to call for students to explore diversity including their own diversity and the effect that their cultural background has on their personal and professional lives. A concrete objective should be for social work students to be knowledgeable about different perspectives of parenting and discipline and to be familiar with the historical context of those 
perceptions. For example, students should know that what is often seen as harsh physical discipline in the Black American family was used historically as a protective mechanism against the harsher reality of White dominated society and against the dangers of street culture (Boyd-Franklin, 1989). It is important for students to recognize that tolerance of physical punishment by persons of color is a reflection that the world is often different for families of color than it is for white families. In addition to being familiar with different cultural perspectives of parenting, students should be required to examine the effectiveness or lack thereof of various types of parenting by reviewing the research outcomes of discipline and child rearing practices based on culturally held norms.

Clearly, professional socialization does not stop with an advanced degree; rather it is ongoing and the findings of this research have implications for the continued professionalization of the child welfare system and for continuing professional education. A number of states, including New York, have made efforts to professionalize the public child welfare workforce (Barbee et al., 2009; Sar et al., 2008). This study suggests that those efforts should be maintained and that social workers are well suited to child welfare work, in that they can make informed decisions based on their professional training rather than personal opinion. The findings of this research also have implications for in-service training. In this study, in-service training was related to a higher approval of corporal punishment. This correlation does not indicate a cause/effect but rather the fact that "hours of training" is related to ethnicity, with minority workers receiving more training than Whites, perhaps in recognition of the discordance between their personal beliefs and practice expectations or in recognition that social workers of color had fewer years of experience than Whites. Training showed no correlation with either perceptions of maltreatment, or likelihood of reporting. These findings suggest that social welfare agencies are challenged to provide the kind of training that is tailored to improve the fit between attitudes and professional behavior. Moreover, social welfare agencies should include training that helps workers identify their personal opinions and attitudes, explore the bases of those attitudes, and explore the possible effects those attitudes have on practice.

The study does raise questions. For example, are the differences among ethnic groups in terms of their personal attitudes toward discipline and perception of maltreatment a result of differential socialization? Further research is needed to explore this issue and to find ways for social work education to enhance professionalization for all groups. In addition, one wonders if the disharmony between thought and action among non-White social workers results in a tension that social workers of color experience in daily practice. If such a tension exists, is there a psychic toll required of the worker to resolve that disharmony? On the other hand, the difference between the private self, i.e. attitudes and beliefs, and the public professional self, may be an indication of two social work skills-self-awareness expressed in the ability to objectively assess oneself, and selfcontainment expressed in the ability to set aside personal attitudes and beliefs and put into practice the norms and values of the profession. It is left to future research to identify those factors that lead workers to put aside their private opinions and to do what is right in terms of professional conduct. 


\section{References}

Abrams, L. S., \& Gibson, P. (2007). Teaching notes. Reframing multicultural education: Teaching White privilege in the social work curriculum. Journal of Social Work Education, 43(1), 147-160.

Abrams, L. S., \& Mojo, J. A. (2009). Critical race theory and cultural competence dilemma in social work education. Journal of Social Work Education, 45(2), 245261.

Ashton, V. (1999). Worker judgements of seriousness about and reporting of suspected child maltreatment. Child Abuse \& Neglect, 23(6), 539-548.

Ashton, V. (2001). The relationship between attitudes toward corporal punishment and the perception and reporting of child maltreatment. Child Abuse \& Neglect, 25(3), 389-399.

Ashton, V. (2004). The effect of personal characteristics on reporting child maltreatment. Child Abuse \& Neglect, 28(9), 985-997.

Barbee, A. P., Antle, B., Sullivan, D. J., Huebner, R., Fox, S., \& Hall, J. C. (2009). Recruiting and retaining child welfare workers: Is preparing social work students enough for sustained commitment to the field? Child Welfare, 88(5), 69-86.

Barretti, M. A. (2003). The professional socialization of undergraduate social work students: an exploratory case study. Unpublished doctoral dissertation, City University of New York.

Bluestone, C. (2005). Personal disciplinary history and views of physical punishment: implications for training mandated reporters. Child Abuse Review, 14(4), 240-258.

Boyd-Franklin, N. (1989). Black families in therapy. New York, NY: The Guilford Press.

Cohen, J. (1988). Statistical power analysis for the behavioral sciences. Hillsdale, NJ: Lawrence Erlbaum Associates.

Costello, C. Y. (2004). Changing clothes: Gender inequality and professional socialization. NWSA (National Women's Studies Association) Journal, 16(2), 138155 .

Council on Social Work Education. (2008). EPAS Handbook. Retrieved from: http://www.cswe.org/File.aspx?id=13780

Daniel, C. A. (2007). Outsiders-within: Critical race theory, graduate education and barriers to professionalization. Journal of Sociology \& Social Welfare, 34(1), 25-42.

Danso, H., Hunsberger, B., \& Pratt, M. (1997). The role of parental religious fundamentalism and right-wing authoritarianism in child-rearing goals and practices. The Journal for the Scientific Study of Religion, 36(4), 496-511.

Deater-Deckard, K., Lansford, J. E., Dodge, K. A., Pettit, G. S., \& Bates, J. E. (2003). The development of attitudes about physical punishment: An 8-year longitudinal study. Journal of Family Psychology, 17(3), 351-360. 
Devore, W., \& Schlesinger, E. G. (1999). Ethnic-sensitive social work practice (5 $5^{\text {th }}$ ed.). Needham Heights, MA: Allyn \& Bacon.

Dolliver, M. (2008, July 14). Double vision: The race issue revisited. Adweek. Special Reports.

Gibelman, M., \& Schervish, P. H. (1997). Who we are: A second look ( $2^{\text {nd }}$ ed.). Washington, DC: National Association of Social Workers.

Green, J. W. (1978). The role of cultural anthropology in the education of social service personnel. Journal of Sociology and Social Welfare, 5(2), 214-229.

Hantman, S., Mosek, A., Ben-Oz, M., Cohen, A., Doron, H., \& Farchi, M. (2006). The socialization of social work: A developmental perspective. Social Work Forum, 39(1), 79-100.

Hong, G. K., \& Hong, L. K. (1991). Comparative perspectives on child abuse and neglect: Chinese versus Hispanics and Whites. Child Welfare, 70(4), 463-475.

Ibanez, E. S., Borrego, J., Pemberton, J. R., \& Terao, S. (2006). Cultural factors in decision-making about child physical abuse: Identifying reporter characteristics influencing reporting tendencies. Child Abuse \& Neglect, 30(12), 1365-1379.

Jeffery, D. (2005). 'What good is anti-racist social work if you can't master it'?: exploring a paradox in anti-racist social work education. Race, Ethnicity and Education, 8(4), 409-425.

Johnson, L. C., \& Yanca, S. J. (2007). Social work practice $\left(9^{\text {th }}\right.$ ed.). New York: Pearson Education.

Korbin, J. E. (1994). Sociocultural factors in child maltreatment. In G. B. Melton \& F. D. Barry (Eds.), Protecting children from abuse and neglect (pp.182 -223). New York: The Guilford Press.

Lau, A. S., Takeuchi, D. T., \& Alegri'a, M. (2006). Parent-to-child aggression among Asian American parents: Culture, context, and vulnerability. Journal of Marriage and Family, 68(5), 1261-1275

Mattison, M. (2000). Ethical decision making: The person in the process. Social Work, 45(3), 201-212.

Miehls, D. (2001). The interface of racial identity development with identity complexity in clinical social work student practitioners. Clinical Social Work Journal, 29(3), 229-244.

Morris, J. L., Johnson, C. F., \& Clasen, M. (1985). To report or not to report: Physicians' attitudes toward discipline and child abuse. American Journal of Diseases in Children, 139(2), 194-197.

Mosby, L., Rawls, A. W., Meehan, A. J. Mays, E., \& Pettinari, C. J. (1999). Troubles in interracial talk about discipline: An examination of African American child rearing narratives. Journal of Comparative Family Studies, 30(3), 489-521. 
Rosenthal, J. A. (2001). Statistics and data interpretation for the helping professions. Belmont, CA: Wadsworth/Thompson Learning.

Sar, B. K., Bledsoe, L. K., Sullivan, D. J., Weeks, P. L., Fox, S., Barrett. L. H., Wadlington, K. L., \& Cashwell, S. T. (2008). Professionalizing the child welfare workforce: Kentucky's Credit for Learning (CFL) initiative. Journal of Public Child Welfare, 2(4), 471-494.

Sedlak, A. J., Mettenburg, J., Basena, M., Petta, I., McPherson, K., Greene, A., \& Li, S. (2010). Fourth National Incidence Study of Child Abuse and Neglect (NIS-4): Report to Congress. Washington, DC: U.S. Department of Health and Human Services, Administration for Children and Families.

Smith, D. E., \& Mosby, G. (2003). Jamaican child-rearing practices: The role of corporal punishment. Adolescence, 38(158), 369-381.

Spano, R., \& Koenig, T. (2007). What is sacred when personal and professional values collide? [Electronic version]. Journal of Social Work Values and Ethics, 4(3). Retrieved from: http://www.socialworker.com/jswve/index2.php?option=com_content\&do_pdf=1\&id $\underline{=69}$

Tam, D. M. Y., \& Coleman, H. (2009). Construction and validation of a professional suitability scale for social work practice. Journal of Social Work Education, 45(1), 47-63.

Webb, N. B. (2001). Culturally diverse parent-child and family relationships: A guide for social workers and other practitioners. New York: Columbia University Press.

Zellman, G. L. (1992). The impact of case characteristics on child abuse reporting decisions. Child Abuse \& Neglect, 16(1), 57-74.

\section{Author Note:}

Address correspondence to: Vicki Ashton, D.S.W., York College/CUNY, Department of Social Sciences, Jamaica, NY 11451. Email: ashton@york.cuny.edu 